\title{
HOSPITALIDADE COMO DESCONSTRUÇ̃̃O PELA PARUSIA SEGUNDO JACQUES DERRIDA
}

\author{
Ramiro Délio Borges de Meneses ${ }^{1}$
}

RESUMO: A desconstrução é uma audição, uma decisão e uma recitação da Palavra. Assim, a desconstrução é "abertura da palavra". Também poderemos asseverar que a desconstrução é uma espécie de "maiêutica", dado que há um "parto" da Palavra. Finalmente, poderemos descrever a "desconstrução" como o acolhimento do acolhimento, bem como a hospitalidade da hospitalidade. É o "acolhimento puro". A desconstrução é a soberania da Palavra, é o poder da Palavra e, assim, assume-se como "ouvir a palavra". Esta audição é a "melhor parte", tal como se verificou na hospitalidade de Betânia. Assim, a desconstrução está "por-vir". A desconstrução é o caminho do "por-vir" da Palavra. A desconstrução é hospitalidade e a hospitalidade é desconstrução, sendo a hospitalidade uma "parusia".

PALAVRAS-CHAVE:Derrida;Desconstrução;Ética;Hospitalidade e Parusia.

ABSTRACT: The deconstruction is a hearing, a decision and a recitation of the Word. Thus, deconstruction is "opening the word." We may also assert that deconstruction is a kind of "maieutica" given that there is a "birth" of the Word. Finally, we 
describe the "deconstruction" as the host of the host as well as the hospitality of hospitality. It is the "host pure." Deconstruction is the sovereignty of the Word, is the power of the Word and thus assumed as "hearing the word." This hearing is the "best part", as found in the hospitality of Bethany. Thus, deconstruction is "to-come". Deconstruction is the way of the "to-come" of the Therefore the deconstruction is hospitality and the hospitality is deconstruction, and is founded by the "parusia".

KEYWORDS: Derrida; Deconstruction; Ethics; Hospitality and "Parusia". 


\section{INTRODUÇÃO}

A hospitalidade é uma "parusia" do Outro-estranho para com o anfitrião e vice-versa. Assim, a hospitalidade é quia venturus est do homo mendicans. A hospitalidade é eventum alteri, através de uma relação plesiológica. Quanto ao seu fundamento axiológico e fenomenológico reside numa "esplancnoplesiologia" entre um anfitrião e um estrangeiro. Na verdade, a hospitalidade é o "Zukunft" do Outro. A hospitalidade, segundo Derrida, será, em primeiro lugar, a exposição incondicional e incalculável ao que "acontece", à vinda do que vem, antes de "quoi" (que) ou "quiconque" (qualquer um). Logo, o "que quer que seja" é o acontecimento singular, surpreendente, excepcional, excessivo e inapropriável do que acontece. A este, Derrida chama "tout autre" (totalmente outro) ou "autre absolu" (outro absoluto), porque absolutamente único e separado do horizonte intencional e do tempo cronológico. Acolhê-lo seria acolher para lá da capacidade do "acolhimento", seria acolher mais do que é possível "acolher". Logo, a hospitalidade é um "Unterkunft" (acolhimento) do que "há-de vir" (adventum). É a "parusia" do Outro-estrangeiro, que entra na "minha casa" (chez moi). Na verdade, a hospitalidade incondicional ou o "acolhimento do absolutamente outro" é impossível, porque é impossível ter lugar num espaço-tempo determinado. Se o evento é, para Derrida, a vinda do absolutamente Outro, que chega ou acontece, então ele não pode ser senão impossível, o que quer dizer impossível de imaginar. Se a hospitalidade se refere à capacidade de acolher, no próprio lugar, o estranho e vulnerável, então o grande repto consiste em verificar a situação dos vulneráveis: como é o homo mendicans (homem pedinte). Ser hospitaleiro pressupõe, segundo Derrida, a capacidade de recepção ou do acolhimento 
do Outro. Assim, o conceito de hospitalidade não é estático, é, de preferência, um conceito dinâmico, que nos obriga a sair de nós próprios e das instituições, para poder estar atento à vulnerabilidade do estrangeiro. Derrida procura separar o conceito de pura hospitalidade do conceito de "convite". Se eu te espero e estou preparado para te receber, então implica que não existe surpresa, dado que tudo está em ordem. Segundo Derrida, a hospitalidade é uma descomnstrução, que se revela como uma "parusia", enquanto que para Levinas a hospitalidade é uma ética.

\section{1.}

A pura hospitalidade implica-se na absoluta surpresa, para o acontecer do Outro, como um Messias. Se sou incondicionalmente hospitaleiro, então receberei, naturalmente, a "visita", não o hóspede convidado. Não devo estar preparado, para não estar preparado, para a chegada inesperada, que consiste nesta abertura ao Outro. Se existe a pura hospitalidade, o puro acolhimento, logo deverá ser pura abertura sem horizonte. A hospitalidade não deve pagar uma dívida, nem ser mandada como um "dever" (Pflicht), muito embora não "deva" abrir-se ao hóspede (convidado) nem conforme ao "dever", nem mesmo para utilizar a distinção kantiana "por dever". A lei incondicional da hospitalidade, que a podemos pensar, será uma lei sem imperativo e sem ordem. Segundo Derrida, afirma-se como lei sem lei. É chamamento que notifica sem mandar. Entretanto, se eu pratico a hospitalidade "por dever", esta hospitalidade de pagamento de dívida, que será uma "hospitalidade ética", não implicará uma hospitalidade absoluta ou incondicional. Ela não é graciosamente oferecida, para além da dívida e da economia, como uma oferta ao Outro. 
O estrangeiro (homo mendicans) deve necessitar da hospitalidade numa linguagem, que, por definição, não será a sua, mas aquela que lhe impõe o dono da casa (anfitrião), o hospedeiro/hóspede, o rei, o senhor, o poder, a nação, o Estado, o pai, o pater familias Para Derrida, deveremos pedir ao estrangeiro para que nos entenda, falando a nossa língua, em todos os sentidos deste termo, em todas as suas extensões possíveis, a fim de o poder acolher. Assim se compreenderá o papel da hospitalidade, na estrutura da alteridade, que se adjudica à desconstrução.

\section{2.}

A lei da hospitalidade, como lei incondicional, vive-se ilimitadamente ao dar ao "chegante" toda a "sua casa" (chez-soi) e, quer ao anfitrião, quer ao estrangeiro, sem lhe pedir nem o nome, nem contrapartidas, nem realizar a menor condição ,e, por outra parte, tendo direitos e deveres condicionados e condicionantes, tal como foi apanágio das tradições greco-latinas e judaico-cristãs. Derrida dirá que, entretanto, há uma relação directa entre a hospitalidade tradicional e a hiperbólica. Os actos da hospitalidade condicional só acontecem à sombra da impossibilidade da sua versão ideal. Esta ideia de incondicional/impossível encontra-se presente na obra tardia de Derrida: a satisfação, o duelo, o perdão, etc. Como refere Derrida, a hospitalidade, no uso que Levinas faz deste termo, não se reduz simplesmente, ainda que também o seja ao "acolhimento do estrangeiro" no lugar, na própria casa, na sua nação, na sua cidade. Desde o momento em que me abro, faço o "acolhimento", para retomar o termo de Levinas, como "alteridade do Outro" e, assim, já estou numa disposição hospitaleira. A própria xenofobia implica que eu tenha que ver com o Outro e, 
desta forma, já estou "aberto ao outro". O encerramento não é mais do que uma reação a uma primeira abertura. Na verdade, a hospitalidade é primeira. É, com efeito, a grande categoria ética, porque, segundo Derrida, toda a Ética é Hospitalidade e toda a Hospitalidade é Ética. A Lei da Hospitalidade está acima das leis. Ela é, então, transgressiva, fora da lei, como uma "lei anómica", nomos a-nomos, lei acima das leis e lei fora da lei (anomos). Mas, estando acima das leis da hospitalidade, a lei incondicional da hospitalidade tem necessidade das leis, ela requere-as. Ela não será incondicional, como lei da hospitalidade, se não "devait pas devenir" (ela não deverá chegar) efetiva, concreta, determinada, se tal não seja o seu ser como "dever-ser". Para ser aquilo que é, a lei tem, então, necessidade das leis que a negam, a ameaçam, em todo o caso, muitas vezes, pervertendo-a. E devem sempre poder fazêlo. A lei da hospitalidade, a lei formal que orienta o conceito geral de hospitalidade, aparece como uma lei paradoxal, corruptível ou pervertível. Ela parece ditar que a hospitalidade absoluta rompe com a Lei da Hospitalidade, segundo Derrida, como direito ou como dever pelo "pacto" de hospitalidade. Por outras palavras, a hospitalidade absoluta exige que eu abra a "minha casa" (chezmoi) e que me ofereça, não somente ao estrangeiro (provido de um nome de família, de um estatuto social de estrangeiro, etc.), como também ao Outro-absoluto, desconhecido, anónimo e que eu lhe dêlugar, que eu o deixe vir a mim, que eu o deixe chegar e ter lugar no lugar, que eu lhe ofereça a minha casa e o meu ser, sem lhe pedir nem reciprocidade (entrada num pacto), nem mesmo o seu nome.

\section{3.}

A lei da hospitalidade absoluta ou incondicional comanda a rutura com a hospitalidade de direito. Ela poderá condenar ou 
opor-se a ela, podendo, ao contrário, colocá-la num movimento de progresso, mas ela ser-lhe-á, também, estranhamente heterogénea, uma vez que a justiça é heterogénea ao direito, onde ela é, portanto, próxima e, na verdade, indissociável. Com efeito, o direito de hospitalidade, segundo o pensamento derridiano, compromete uma casa, uma linguagem, uma família ou uma etnia. Logo se determina a possibilidade de serem chamados pelo seu nome, serem convidados, serem sujeitos de direito e com direitos, responsáveis e dotados de uma identidade denominável, todos aqueles que usufruem da hospitalidade. Esta chama-se hospitalidade condicional ou relativa. A diferença, uma das diferenças subtis, por vezes não alcançável, entre o Outro-estranho (forasteiro) e o Outro-absoluto, será aquilo porque este último pode não ter nome de família, na "hospitalidade absoluta" ou incondicional, que eu poderei oferecer-lhe. Supõe, portanto, uma rutura com a hospitalidade condicional, como direito ou como pacto de hospitalidade. A hospitalidade é o primeiro momento de toda e qualquer atividade da consciência e da realização ética. Segundo o filósofo das três críticas, a hospitalidade postula o sentido imanente do sentimento do respeito pelo direito natural, fundamento da mesma hospitalidade, que se apresenta, segundo o pensador de Koenigsberg, como não sendo fruto de quaisquer afecções externas, do domínio sensível, mas, de preferência, surge como sentimento interior, que se produz por meio da Razão. Desta sorte, a hospitalidade depende do valor e do sentido da Razão Prática (praktische Vernunft). O acolhimento vem do exercício da lei moral. A hospitalidade, segundo o filósofo de Koenigsberg, "alberga-se" na autonomia da Vontade (Wille). Contudo, a nossa posição refere a hospitalidade, pelo pensamento da Filosofia Pura, como uma heteronomia do Outro-estranho e do anfitrião. Na perspectiva de Kant, a hospitalidade é um 
deontologismo do acolhimento. Na hospitalidade kantiana, está presente o dever ; mas, enquanto entendido como expressão de culturas, foi expresso por Derrida. Segundo Kant, a hospitalidade é «Ueberkunft »( pacto). Trata-se, pois, de um pacto celebrado entre cidadãos e entre Estados. A paixão democrática de Derrida (a democracia por-vir) viveu-se desde a primeira letra, em torno da qual, cultivando-a e cultivando-se, girará a desconstrução em torno de Cosmopolites de tous les pays: encore un effort!, sendo a cena da sua quase exibição : a intempestividade da Ética da Hospitalidade, como hospitalidade, sinónimo de vigília, vida, cultura e "por vir". Será uma Ética que é reinvenção da Ética, uma outra Ética (muito distante da Ética Deontológica de Kant, e mais próxima da Ética como filosofia primeira, de Levinas). Daqui que a hospitalidade será "Auskunft ", descrevendo-se como comunicação teórica, prática e poiética, intersubjetivamente dada e vivida. Na hospitalidade de Betânia, Maria foi o "dom" (a oferta da contemplação) e Marta o "contra-dom" (tarefa). A hospitalidade revela, também, uma "quenose", que aqui será revelada em Jesus Cristo. Jesus Cristo foi, na hospitalidade de Betânia, a "Ankunft" da Soteriologia." O hóspede é "vulnerável", tal como foi Jesus Cristo, personagem central da parábola do Homo Viator, não só porque não tem o que deveria ter para se desenvolver, de um modo ótimo, mas, porque ao "abrir-se a porta", desprende-se do que representa, para se mostrar tal qual é a sua indigência. Os anfitriões de Betânia foram vulneráveis, provando, fenomenologicamente, que a hospitalidade é uma "vulnerabilidade" do ser, do agir e do fazer. A hospitalidade é o reconhecimento da abertura de dois corações, é não só a ordo amoris, como também o amor ordinis. $\mathrm{Na}$ hospitalidade, os corações partem-se, por isso ela é recolhimento, perdão, etc. 
O movimento dos olhos visa o Outro para o reconhecer e acolher. A hospitalidade será o olhar, os lábios, a boca, como sinais de abertura ao Outro. O olhar do que nos quer falar, segundo Levinas, é o olhar que funda a linguagem e não o conhecimento. Assim, o olhar como significação não tende à apreensão das coisas, mas faz-se significação, dirigindo-se a mim. Em todo o momento da imanência e da historicidade, a epifania do Rosto é uma "visitação". A abertura é um desnudamento, que nos torna mais vulneráveis. Segundo Levinas, a hospitalidade é o "desejo do Outro", porque será "dar prioridade ao Outro. O anfitrião dá prioridade ao homo mendicans. Para Levinas, a hospitalidade supõe a "responsabilidade anárquica", muito embora a sua vivência se situe numa responsabilidade plesiológica, que é uma "responsabilidade poiética". A partir da "responsabilidade poiética" surge um paradigma para a humanização em saúde, delineado em três dimensões, a saber: responsabilidade pística, responsabilidade elpídica e responsabilidade agápica, que se encontra presente na relação médico-doente. A Hospitalidade, como desconstrução, permitirá primeiramente a "construção do acolhimento", que reside no castellum, como sucedeu em Betânia. Para haver hospitalidade, terá de haver uma "casa" (moradia), a fim de o anfitrião receber o Outro-estranho e viceversa. Toda a hospitalidade, pela desconstrução, necessita da construção (edifício) para haver o acolhimento. A hospitalidade é simultaneamente uma construção e uma desconstrução. A hospitalidade terminará numa reconstrução entre o anfitrião e o homo mendicans. Entretanto, a desconstrução depende da "construção". Assim, se passa no acolhimento em saúde, 
onde encontramos, como paradigma, a trilogia: construção, desconstrução e reconstrução. Na hospitalidade, somente depois de haver a oikia (casa), então é que haverá "desconstrução do outro-estranho" pelo anfitrião. Deve revelar-se, na hospitalidade, como desconstrução, a construção intersubjetiva entre o anfitrião e um Desvalido no Caminho. Esta será a grande critica ao pensamento de Derrida, segundo a nossa perspetiva, uma vez que a desconstrução terá de implicar uma "recitação elpidica", visto que per se a desconstrução é uma "audição da palavra" (escrita e falada). A desconstrução será, também, "ouvir o hóspede". A hospitalidade é uma intersubjetividade dual, simultaneamente construtiva e desconstrutiva. Interpretando o pensamento de Derrida, teremos de salientar que a hospitalidade surge como possibilidade do estar dentro ou no interior da possibilidade. Logo, será a possibilidade da possibilidade. Toda a hospitalidade, como possibilidade do im-possivel, será a possibilidade da desconstrução do Outro-estranho, através do anfitrião, cabendo aqui a desconstrução do "host" (dono da casa) no "guest" (convidado,hóspede) e vice-versa. Ao longo da sua obra, Derrida tentou demonstrar como a hospitalidade incondicional desconstrói a hospitalidade desejada do hóspede-cidadão, que se pretende ser o mestre do lugar, onde ela oferece o lugar ao desconstruir uma espécie de ipsocracia, legada posteriormente na sua singularidade impossível do "otage" (refém), do recémchegado, do antes mesmo da sua condição de cidadão e do antes da polis (cidade-estado) e, desta sorte, posteriormente a uma tal hospitalidade incondicional do antes e do depois da hospitalidade condicional ou jurídico - politica, que ela seja, como salienta Kant, cosmopolita, e que se encontre como "oportunidade" (Gelegenheit) para pensar e repensar, de outra forma, a ipseidade, 
a cidadania, o direito nacional e internacional. Pela nossa reflexão, a desconstrução é uma audição, uma decisão e uma recitação da Palavra. Toda a hospitalidade é uma "parúsia". È aquilo que "está para vir", desde a palavra à vida. Será a "parúsia" do Outro estranho, diante do anfitrião e vice-versa, no domínio da casa.

\section{5.}

Assim, a desconstrução é "abertura da palavra". Também poderemos salientar que a desconstrução é uma espécie de "maêutica", dado que há um "parto" da Palavra. Finalmente, poderemos descrever a "desconstrução" como o acolhimento do acolhimento, bem como a hospitalidade da hospitalidade. É o "acolhimento puro". Na verdade, a desconstrução é abrir e fechar o texto e a realidade. É o tudo ou o nada da realidade e do texto. É, com efeito, o "talvez" do texto e da realidade. É o "talvez" da Palavra, da "audição da palavra" e do "ouvir o hóspede". A desconstrução tem um antes na "construção" e um depois na reconstrução, para ela mesma surgir como desconstrução, pela síntese da realidade e do texto. A desconstrução é a soberania da Palavra, é o poder da Palavra e, assim, assume-se como "ouvir a palavra". Esta audição é a "melhor parte", tal como se verificou na hospitalidade de Betânia. Esta caracteriza a desconstrução. Assim, a desconstrução está "por vir". A desconstrução é o caminho do "por vir" da Palavra. Desta feita, a desconstrução é uma "paixão inventiva", tanto do criador literário quanto do filósofo. Este pensamento inventivo é hipotético e move-se por baixo da tese. Pela desconstrução, o venire do por-venire revela-se ao venire do in-venire. A desconstrução é o in-venire. Esta, como "invenção", 
só pode ser pensada juntamente com o dom. Naturalmente, a desconstrução é a síntese dialéctica entre uma construção (tese) e uma reconstrução (antítese). A desconstrução é o movimento do pensamento". Um pensamento do "talvez", um pensamento contaminado. A desconstrução será o "pensamento por vir". Poderemos ainda dizer que a "desconstrução" é um já e um ainda não do pensamento. É, pois, uma espécie de "escatologia" do pensamento e um pensamento como Escatologia. O mundo da saúde e da doença, através da humanização hospitalar, é uma desconstrução. O pensamento clínico é sempre um pensamento "por vir", visto que é um "por vir" da Medicina, dado que esta é uma arte e uma ciência. Uma das aplicações da desconstrução, no mundo das artes e das ciências, reside na Medicina e, de forma explícita, no acolhimento em saúde. A hospitalidade incondicional será a incondicionalidade do Outro-estranho no anfitrião e vice-versa. A hospitalidade incondicional revela-se como o acolhimento do acolhimento. Será a "soberania do acolhimento". Toda a hospitalidade, como se manifestou no acolhimento de Betânia, surge como uma "relação de relações plesiológicas" de um Senhor (anfitrião) com um súbdito (homo mendicans). A hospitalidade é uma "soberania" que está "por vir". Por isso, toda a hospitalidade é Ética, como vida, como cultura, como um "talvez" do acolhimento. A hospitalidade é uma outra Ética. É a vida da Ėtica e a Ética da Vida. É um "talvez" da Ética. Uma das visualizações da hospitalidade é oferecida pelo acolhimento em saúde, que caracteriza a humanização hospitalar. Um dos seus aspetos terá a ver com a incondicionalidade da hospitalidade, uma vez que a humanização em saúde é uma hospitalidade. $\mathrm{O}$ acolhimentio clínico poderá ser incondicional, sem convite. Mas também poderá ser condicional. As patologias e as exigências 
diagnósticas impelem, per essentiam, a uma hospitalidade clínica, particularmente nos cuidados primários. O doente é um "recémchegado" (arrivant) sem condições. A doença é uma situação incondicional, quer para o médico, quer para o doente. Assim, o acolhimento clínico (relação médico-doente) é determinado por uma "desconstrução incondicional", que se chama "hospitalidade incondicional" na humanização em saúde. A hospitalidade é um "acolhimento poiético", porque exige uma "espera", que é preparação para o acolhimento. Esta hospitalidade é "elpídica", uma vez que há uma conversão para aquilo que "há-de vir". A hospitalidade é um "Zukunft" elpidofânico do acolhimento ou do recebimento do Outro, tal como Jesus se acolheu com Marta e Maria.

6.

A hospitalidade é uma recitação elpídica do Outro. O Outro acolhe-se! É recitado pela espera do anfitrião. A recitação elpídica é a hospitalidade e esta supõe, dialecticamente, a audição (contemplação) e a decisão (acção agápica). Maria traduz a audição ao estar sentada aos pés da Palavra (Jesus Cristo), para alcançar a "decisão", que será a caridade ao próximo. Aqui temos um modelo de humanização em saúde, que se denomina "recitativo elpidofânico". Quando se recebe alguém em casa, procura-se fazer o melhor para receber o visitante. Foi este o sentido da hospitalidade em Betânia. Não passa pela cabeça de ninguém, que uma pessoa, que decide (caridade) receber alguém, em sua casa, comece a queixar-se à sua visita, que está a trabalhar de mais, que está cansada e que mande alguém ajudá-la no serviço, que está fazendo as "honras da casa" Como se reagiria, perante uma 
atitude destas, a visita? O apólogo de Betânia é um texto artificial à luz dos códigos de receção de visitas. Nem Simão, no episódio da unção da pecadora arrependida, em Lc.7,36-50, com as suas faltas de hospitalidade, denunciadas por Jesus, se queixa de ter tido muito trabalho, ele ou o seu pessoal, para acolher o hóspede "divino" em sua casa. Aquela que escolheu a melhor parte, foi a mais hospitaleira. Segundo a hospitalidade, que Marta signifique a vida ativa e Maria a vida contemplativa, são estereótipos funcionais para referir uma leitura teologal, que estabeleceu os dois destinos destas mulheres de Betânia. A hospitalidade faz-se no feminino, como reclama Levinas, e é mais maternal, do que paternal. Necessita da presença e da inovação da Mulher, tal como revela nos relatos neotestamentários. A exegese posterior encontrará aqui a proclamação da superioridade da "contemplação" sobre a "ação". Neste texto, sobre a hospitalidade de Betânia, não se trata de contemplar, mas antes "escutar a Palavra", que chama à fé e à adesão à mesma. A hospitalidade é uma escuta da Palavra e a Palavra é Jesus Cristo. Na hospitalidade, há uma "solicitude poiética" que significa a prioridade que se dá ao Outro. Mas este é um acolhimento, que vai da escuta à contemplação do Outro. Daqui encontrarmos um outro paradigma para a humanização em saúde, que surge da relação contemplação - acção na relação médico - doente, que se chamará de "contemplação poiética" A hospitalidade condicional será um compromisso com o Outro, um compromisso pré-determinado, por convite, de tal forma que poderemos denominar esta como sendo uma "responsabilidade poiética", tal como surge na hospitalidade extrínseca (impura ou condicional), traduzida na parábola do Bom Samaritano (Lc.10,25-37). Esta forma de hospitalidade é per accidens. Surge 
como in vita contingens maxime (maximamente contingente na vida). Na verdade, a hospitalidade condicional estará ligada a uma hospitalidade "por convite", tal como a abrahamica, narrada no livro do Genesis (18,1-15). Abraham significou, ao receber os "três visitantes misteriosos", uma forma de hospitalidade de prefiguração, entre a condicional e a incondicional, sendo a síntese das duas anteriores. Surge, de facto, numa "hospitalidade ética", para usar a terminologia de Derrida. Com efeito, trata-se de uma hospitalidade relativa, que vai da sociologia ao direito, passando pela política, sem esquecer a filosofia.

\section{7.}

A hospitalidade condicional é uma hospitalidade acidental, podendo descrever-se como hospitalidade de ocasião, porque não é permanente, estando dependente do "convite". Há um esse ad vivencial entre o anfitrião e o Outro-estranho, que será acolhido. Influenciados, pela desconstrução dos textos dos sinópticos, poderíamos apresentar uma nova tipologia classificativa para a hospitalidade, em hospitalidade de identidade e hospitalidade de alteridade. Ahumanizaçãoemsaúde, atravésdoacolhimentoclínico, no domínio da Medicina Profiláctica, vive da "hospitalidade de convite". Aqui temos o exemplo de uma hospitalidade condicional. O médico convida o doente e família para um controlo, seja na saúde, seja na doença, permitindo-se uma "prevenção clínica". A hospitalidade é uma experiência da amizade primeira, o encontro da presença in actu (em acto), que descreve a análise da hexis (hábito) e de qualquer predisposição, como os outros graus 
da amizade, que a caracterizam com dimensão aretológica. A hospitalidade, segundo o pensamento de Derrida, é um "por vir" da amizade e será um "por vir" do acolhimento. Naturalmente, a amizade pode determinar a hospitalidade, tornando-a mais forte e mais eficaz. Com efeito, Derrida superou as aporias da hospitalidade através do conceito de teleia philia (amizade de perfeição), que é oriunda do pensamento aristotélico, como se poderá descrever pelo pensamento do Filósofo: "a presença dos amigos parece, contudo, ter uma natureza mista. Ver os amigos é afável, sobremaneira quando se passa um momento infeliz, ...". A hospitalidade é uma "relação de alteridade", que nada tem a ver com a indiferença. A amizade dá forma à hospitalidade, dado que a antítese da hospitalidade será a "quenose" do Outro, como um desejo de destruição, um certo "impulso fanático", que mina a hospitalidade. Na hospitalidade regista-se uma manifesta afeição entre a singularidade plural dos sujeitos em presença. Querem o bem uns dos outros. Segundo a nossa perspetiva, a amizade, no domínio da hospitalidade, pertence à "mundividência elpídica", referindo-se ao mundo da espera e da esperança. Tal como o perdão, a hospitalidade convida a uma "resposta". Será um convite ao arrependimento, à conversão, à amizade. Se alguma reinvenção é operada pela hospitalidade, será a de fazer "viver juntos" um "bem viver juntos" e desta uma relação de amizade. A hospitalidade será um "bem viver juntos". A hospitalidade é amizade. A hospitalidade, como "responsabilidade elpídica", possui estes caminhos. São, também, caminhos de humanização em saúde, uma vez que aqui há o "desejo da palavra clínica", que vai da anamnesis (recordação de sinais e de sintomas) até à terapêutica, que constitui o serviço desinteressado do médico, traduzido em tarefas clínicas: diagnóstico e terapêutica. 
Toda a hospitalidade e toda a humanização são uma espera e uma esperança. Esta é uma pergunta do doente na espera da cura (cure) e dos cuidados (care) e uma resposta clínica do médico à esperança do doente. Tudo isto significa que, ao referirse à terapia e à terapêutica, será uma "narração elpídica", que se constitui como "responsabilidade elpídofânica". Trata-se, pois, de uma conversão ao "que há de vir". A esperança é quia venturus est. Será, com efeito, a resposta ao que há de vir (terapêutica). Assim, segundo este momento da humanização em saúde, como "responsabilidade elpídica", faz-se a síntese da "responsabilidade diaconal" (terapia e terapêutica), pela procura dos cuidados e da cura, com a "responsabilidade pística", caracterizada por "ouvir o hóspede" (doente, drogado, miserável, pobre, etc.), pela "audição das palavras", quer do médico, quer do doente, através da anamnesis. Aqui temos um outro modelo de humanização em saúde, manifestado na "responsabilidade poiética", como "responsabilidade elpidofânica". A "responsabilidade elpídica" descreve-se, clinicamente, pelo diagnóstico e pelo prognóstico.. A esperança, ao implicar um certo risco, traduz-se num salto para o futuro e para uma atitude de confiança. A esperança induz um certo grau de incerteza, que advém do diagnóstico e do prognóstico. Poderemos, pois, afirmar que, na humanização em saúde, o diagnóstico implicará a "responsabilidade elpídica" do médico. Nunca esqueceremos que a humanização, em saúde, inclui a fórmula inaciana in actione contemplativus (contemplativo na ação), tendo como base a formulação tomista ex abundantia contemplationis activus ( ser ativo a partir da abundância da contemplação). A "contemplação perfeita" conduz 
à dimensão agápica, visto que se expressa como fecundidade da contemplação pura, não sendo um privilégio exclusivo desta.

\section{9.}

A humanização em saúde é um "projeto elpídico", onde se acolhe o Outro (doente), na "própria casa", significando oferecerlhe um espaço e um tempo elpídicos (esperança) para recuperar da doença, que enfrenta. A humanização em saúde é uma hospitalidade,peressentiam, e, segundooesquemado "acolhimento litúrgico", ao modo de Marta, terá um paradigma inspirado no quadro semântico da "ação", segundo Lucas, que, dialeticamente, se apresenta na relação entre "beneficiar", "servir" e "dar". Esta triangulação, além de definir uma "ética narrativa" do Evangelho, segundo Lucas, é uma forma adequada para esquematizar um original modelo para a humanização dos cuidados. Tanto a hospitalidade, quanto a humanização em saúde, são um "serviço plesiológico". Apresenta um texto que é "escrito", que é um "passado", numa falsa aparência de presente, que é presente, segundo Derrida, ao leitor como seu "avenir" (futuro). A escrita é raconto da doença em todas as dimensões, mas as linguagens são tríplas. Em primeiro lugar, há uma "linguagem anamnética", que se caracteriza pela recolha de sintomas ou queixas do doente, num discurso entre o vernáculo e o técnico. Existe uma gramática e um estilo. Tem um fundamento, muito embora marcado pela subjetividade. Naturalmente, revela-se como linguagem semiológica (fala e discurso sobre queixas). Em segundo lugar, surge uma "linguagem diagnóstica". Esta define-se como uma linguagem quedescrevemétodoscientíficos parao estabelecimento de uma causalidade eficiente e final, decifrando a natureza de uma enfermidade (radiologia, análises clínicas, biópsia, etc.). 


\section{CONCLUSÃO}

A axiologia desta linguagem viabiliza o valor do estabelecimento de um diagnóstico, proporcionando uma base lógica para o tratamento e para o prognóstico. Uma vez que é uma "linguagem semiótica" (visão de sinais), formalmente apresenta-se como o termo que denota o nome da doença ou de síndrome sofrida. É a grande linguagem da Medicina, que lhe garante a cientificidade. Em terceiro e último lugar, temos a "linguagem prognóstica" (conhecimento antecipado). Este conhecimento prévio é uma espécie de antecipação do desfecho de uma patologia. É a previsão do desfecho do decorrer de uma doença. Esta nota da previsibilidade fenoménica de uma doença é uma característica da ciência, da sua cognoscibilidade. A Medicina participa destes três graus linguísticos. A linguagem diagnóstica é marcada pelo presente, sendo a anamnética lida no passado e, finalmente, a "linguagem prognóstica" refere a dimensão do futuro. Sem estas três linguagens não haverá Medicina. Seguindo pela linguagem de Derrida, a Medicina não é uma "double science", mas antes uma "triple science". A Medicina, ao viver da desconstrução, que é dada pela "linguagem diagnóstica”, naturalmente, postula uma construção, que tem o seu valor e limite na "linguagem anamnética", determinando a "linguagem prognóstica" no caminho da recuperação do doente. O acolhimento em saúde é o acolhimento da desconstrução da doença, para se atingir a reconstrução da saúde e da vida. Logo, o acolhimento em saúde é uma desconstrução de desconstrução entre as doenças e a vida saudável. Mas, segundo a Medicina, não há doenças, há doentes. Logo, o acolhimento em saúde será uma desconstrução do doente na sua totalidade. A harmonia do saber concreto e positivo de cada doente, em Medicina, salienta-se 
como uma euroia. Esta euroia vai desde o pensamento teórico, até ao prático, passando pelo poiético. A desconstrução será um pensamento in fieri, dotado de "equilíbrio" entre todas as partes e todos os sujeitos concretos envolvidos. A desconstrução descobre-se como uma euroia das linguagens clínicas (linguagem anamnética, linguagem diagnóstica e linguagem prognóstica). Há na desconstrução, simultaneamente, a preparação de uma linguagem construtiva (história clínica) e uma linguagem reconstrutiva (terapêuticas médicas e cirúrgicas). A hospitalidade manifesta-se, pois, como uma "Gelegenheit"( oportunidade). É uma oportunidade poiética de um estrangeiro diante de um anfitrião e, ainda, uma "Anwesenheit" (presença). É a presença do cum entre o anfitrião e o homo mendicans e viceversa. É a presença do quia venturus est, que se define como um movimento elpídico. Toda a hospitalidade é uma parusia, tal como se verificou na narrativa de Betânia (Lc.10, 38-42).

\section{NOTA}

${ }^{1}$ Doutor em Filosofia - Especialidade de Éticas Aplicadas; Professor de Bioética e de Filologia Clássica, bem como de História da Medicina e da Farmácia no Instituto Superior de Ciências da Saúde do Norte - Gandra - PORTUGAL; Investigador do Centro de Estudos Filosóficos e Humanísticos na Faculdade de Filosofia da Universidade Católica Portuguesa. Correspondência: borges272@ gmail.com; ramiro.meneses@ipsn.cespu.pt 


\section{REFERÊNCIAS}

BERNARDO, F. “A crença de Derrida na justiça Para além do direito, a justiça”, in: AGORA - Papeles de Filosofia, Santiago de Compostela, 28/2, 2009, p.60.

DERRIDA, J. De la Grammatologie, Paris: Les Éditions de Minuit, 1967.

DERRIDA, J. Marges de la Philosophie, Paris: Les Éditions de Minuit, 1972.

DERRIDA, J. Positions. Entretiens, Paris: Les Éditions de Minuit, 1972.

DERRIDA, J. De l'hospitalité, Anne Dufourmantelle invite Derrida à répondre, Paris: Calmann-Lévy, 1977.

DERRIDA, J. D'un ton apocalyptique, adopté naguère en philosophie, Paris: Éditions Galilée, 1983.

DERRIDA, J. Psyché, Inventions de l'autre. II., Paris: Éditions Galilée, 1987.

DERRIDA, J. L'Autre Cap. suivi de la Démocratie Ajournée, Paris: Les Éditions de Minuit, 1991.

DERRIDA, J. Points de suspension. Entretiens, Paris: Éditions Galilée, 1992.“

DERRIDA, J. Passions, Entretiens avec Henri Ronse et al., Paris: Éditions Galilée, 1993. 
HOSPITALIDADE COMO DESCONSTRUÇÃO PELA PARUSIA SEGUNDO JACQUES DERRIDA

DERRIDA, J. Spectres de Marx. L'État de la dette, le travail du deuil et la nouvelle internationale, Paris: Éditions Galilée, 1993.

DERRIDA, J. Donner la mort, Paris: Éditions Galilée, 1999.

DERRIDA, J. Politiques de l'amitié. suivi de L 'oreille de Heidegger, Paris: Éditions Galilée, 1994.

DERRIDA, J. Force de loi. Le Fondement mystique de l'autorité, Paris: Éditions Galilée, 1994.

DERRIDA, J. Moscou aller-retour, Paris: Éditions de l'Aube, 1995.

DERRIDA, J. Résistences de la psychanalyse, Paris: Éditions Galilée, 1996.

DERRIDA, J. Le monolinguisme de l'autre, Paris: Éditions Galilée, 1996.

DERRIDA, J. Apories, Paris: Éditions Galilée, 1996.

DERRIDA, J. Cosmopolites de tous les pays, encore un effort!, Paris: Éditions Galilée, 1997

DERRIDA, J. Le droit à la philosophie du point de vue cosmopolitique, Paris : Éditions Unesco, 1997.

DERRIDA, J. Adieu à Emmanuel Levinas, Paris: Éditions Galilée, 1997.

DERRIDA, J. Manifeste pour l'hospitalité, Paris: Éditions Paroles d'Aube, 1999. 
DERRIDA, J. Le toucher, Jean-Luc Nancy, Paris: Éditions Galilée, 2000.

DERRIDA, J. Foi et Savoir. suivi de Le Siècle et le Pardon, Paris: Éditions du Seuil, 2000.

DERRIDA, J. De quoi demain ... Dialogue, Paris: Librairie Arthème Fayard; Éditions Galilée, 2001 (colab. E.Roudinesco).

DERRIDA, J. Papier Machine, Paris: Éditions Galilée, 2001.

DERRIDA, J. L 'Université sans condition, Paris: Éditions Galilée, 2001.

DERRIDA, J. Fichus, Discours de Francfort, Paris: Éditions Galilée, 2002.

DERRIDA, J. Genèses, généalogies, genres et le génie. Les secrets de là archivent, Paris: Éditions Galilée, 2003.

DERRIDA, J. Le souverain Bien, texto bilingue. Tradução de Fernanda Bernardo, Viseu: Palimage Editores, 2004.

DERRIDA, J. Sob palavras: Instantâneos Filosóficos. Tradução de Miguel Serras Pereira, Lisboa:Fim de Século,1999.

RECEBIDO: $11 / 05 / 2014$ 